\title{
AS UNIDADES ESPECIALIZADAS POLILÉXICAS NOMINAIS (UEPNS) NOS MANUAIS DE AVIAÇÃO
}

\author{
Ana Eliza Pereira BOCORNY*
}

- RESUMO: O objetivo do presente trabalho é apresentar e caracterizar as unidades especializadas poliléxicas nominais (UEPNs), como parte de um trabalho maior que é a elaboração de um glossário para estudantes de um curso de inglês para aviação. Iniciamos o artigo abordando a questão da diversidade denominativa e conceitual associada às UEPNs. Como não há unanimidade na literatura sobre o assunto, procuramos esclarecer onde a diferença denominativa realmente corresponde a uma diferença conceitual. Em seguida, tratamos da caracterização formal das unidades, apresentando os elementos que podem constituí-las e as relações entre eles. Por fim, revisamos a literatura quanto a problemas e soluções relativos à interpretação das UEPNs, geralmente resultantes da grande compactação de informação em um número restrito de palavras, o que torna o entendimento dessas unidades ainda mais complexo quando se trata de um público não especializado. Para tanto, são abordados os trabalhos de autores como Downing, Sager, Lehrberger, Trimble e Shawcross. Encerramos retomando algumas questões que deverão ser levadas em conta quando da interpretação das UEPNs, apoiada em uma matriz de relações semânticas para a análise dessas unidades no âmbito da aviação.

- PALAVRAS-CHAVE: Linguística. Terminologia. UEPN. Tradução. ESP. Linguagem da aviação.

\section{Introdução}

A interpretação de compostos nominais tem sido objeto de muitos trabalhos de pesquisa em diferentes áreas do conhecimento. Para o ensino de linguagens de especialidade, o objetivo é fazer com que os alunos consigam interpretar ou decodificar essas unidades complexas de forma a gestionar melhor sua comunicação especializada no contexto profissional.

O presente artigo é parte de um estudo preliminar para a elaboração de um glossário de termos de aviação a ser disponibilizado online para estudantes de um curso de Inglês para Fins Específicos (English for Specific Purposes, ESP) para a área. Neste trabalho, temos como motivação os alunos e suas dificuldades em identificar e interpretar as unidades especializadas poliléxicas nominais (UEPNs) no conteúdo dos textos especializados dos manuais de aviação.

* PUC-RS - Pontifícia Universidade Católica do Rio Grande do Sul. Faculdades de Letras e Ciências Aeronáuticas. Porto Alegre - RS - Brasil. 90619-900 - ana.bocorny@pucrs.br 
Iniciamos detectando a existência de controvérsia nas denominações sobre os termos especializados, em geral compostos nominais, nos quais, em grande parte dos casos, cada elemento constituinte não induz à dedução do significado expresso pelo todo, que é um conceito único.

Procurou-se, também, analisar os critérios de classificação para essas UEPNs. Cabré e Estopà (2005) propõem seis características básicas para essa classificação. Outros autores, porém, se concentram na análise da estrutura, constituída de determinante, pré-modificador, substantivo e pós-modificador.

A existência de pré-modificadores múltiplos, por exemplo, principalmente no caso da língua inglesa, pode tornar o estudo das UEPNs mais complexo devido às inúmeras relações de sentido que se podem estabelecer entre eles. Por outro lado, as bases nominais tendem a se tornar o ponto central da elaboração de classificação por classes conceituais, já que essas estruturas sempre se concentram em torno de um substantivo.

A principal dificuldade no ensino das UEPNs consiste na grande compactação de informações em um número reduzido de palavras, o que se agrava quando os leitores não possuem o domínio do conhecimento técnico que dá conta dessa complexidade, que é o caso do corpus estudado na nossa pesquisa.

Visando esclarecer essa relação, apresentamos uma revisão da literatura sobre o assunto com o objetivo de trazer algumas colocações clássicas sobre a interpretação de compostos nominais. Para tanto, são abordados autores como Downing (1977), Sager, Dungworth e McDonald (1980), Lehrberger (1982), Trimble (1985) e Shawcross (1992a, 1992b). Além disso, procuramos mostrar como essa interpretação tem sido tratada em textos especializados e verificar se as relações semânticas estabelecidas em textos não especializados são suficientes e aplicáveis ao âmbito especializado.

\section{Diversidade denominativa e conceitual}

Uma das maiores dificuldades encontradas ao fazer a revisão bibliográfica sobre o tema em questão foi buscar unanimidade com relação à denominação das unidades com sentido especializado. Essa diversidade denominativa pode ou não corresponder a uma diversidade conceitual. Quiroz (2005, p.9) refere ter encontrado aproximadamente 90 denominações diferentes ${ }^{1}$ para o que ele mesmo chamaria de sintagmas nominales extensos especializados ou SNEE. Algumas dessas denominações são sintagma nominal compuesto (OSTER, 2003), unités terminologique complexes (CAFÉ, 1999), unité terminologique

Por exemplo: noun phrases with multiple modifiers ou compound nouns (inglês); syntagmes nominaux complexes (francês); sintagma nominal compuesto (espanhol). 
polylexicales (ESTOPÀ, 2001) e unidades terminológicas complexas (FAULSTICH, 2003).

Traços comuns unem essas denominações. As palavras compuesto/ complexes/polylexicales/complexas, por exemplo, ressaltam o fato de as unidades serem formadas por mais de um elemento constituinte. As palavras terminológicos/terminologique/terminológicas, por sua vez, destacam o fato de as unidades fazerem parte do léxico de uma área de especialidade, na medida em que representam conhecimento especializado. Por fim, sintagma/unidades/ unité chamam a atenção para a vinculação existente entre os vários elementos constituintes da unidade.

Na língua inglesa, as palavras compound e noun/nominal destacam-se na formação de várias denominações para as unidades poliléxicas nominais, ${ }^{2}$ ressaltando o fato de essas unidades terem mais de um elemento constituinte e possuírem substantivos como base ou modificador(es), conforme Quadro 1.

Quadro 1 - Denominações da língua inglesa

\begin{tabular}{|l|}
\hline \multicolumn{1}{|c|}{ Denominações em inglês } \\
\hline Noun+noun compound (DOWNING, 1977) \\
Compound nouns (DOWNING, 1977) \\
Complex nominal (LEVI, 1978) \\
Nominal compound (FININ, 1980) \\
Noun sequences (LEHRBERGER, 1982) \\
Noun phrases with multiple pre modifiers (QUIRK et al., 1985) \\
Complex compounds (TRIMBLE, 1985) \\
More complex compounds (TRIMBLE, 1985) \\
Very complex compounds (TRIMBLE, 1985) \\
Noun phrases with multiple premodifiers (BIBER et al., 1999) \\
Noun phrase (RIJKHOFF, 2002)
\end{tabular}

Fonte: Elaboração própria.

Na literatura em inglês sobre compostos nominais, há controvérsia sobre o que venha a ser um noun compound e um noun phrase. Downing afirma que

2 As palavras "compostos nominais", "unidades nominais" e "unidades poliléxicas" são utilizadas neste trabalho como sinônimos de UEPNs. 
alguns autores se baseiam no critério semântico para traçar essa diferença, dizendo que o fato de representarem um único conceito geralmente distingue noun compounds de nominal phrases. Outro elemento diferenciador seria o fato de o significado de um compound não poder ser deduzido a partir do significado de seus constituintes:

There has been much dispute as to the criteria that should be employed in distinguishing compound forms from 'nominal phrases'. [...] But other authors have relied on semantic criteria, emphasizing the unitary meaning typically associated with compounds (as opposed to nominal phrases), or the fact that the meaning of the compound as a whole typically cannot be deduced from the meanings of its constituents. (DOWNING, 1977, p.810). ${ }^{3}$

Outros autores (GIRJU et al., 2005), para diferenciar os compositional compounds (door knob) dos non-compositional compounds (soap opera), utilizam o critério de dedução do significado a partir dos constituintes. Os noncompositional compounds, também chamados opaque (opacos), são geralmente compostos lexicalizados cujo sentido não pode ser interpretado a partir dos elementos que os compõem.

Para identificar seu objeto de estudo, cada autor faz opções, ressaltando determinados traços característicos da unidade. Biber et al. (1999) usa noun phrases with multiple premodifiers para as unidades com base nominal e múltiplos pré-modificadores. Trimble (1985, p.130) utiliza noun compound para "[...] two or more nouns plus necessary adjectives (and less often verbs and adverbs) that together make up a single concept; that is, the total expresses a 'single noun' idea" ${ }^{4}$ Estopà (1999, p.25) inicialmente adota a denominação unidades de significación especializada (USE), e mais tarde unidades de conocimiento especializado (UCE) (CABRÉ; ESTOPÀ, 2005) para "[... ] unidades que vehiculan conocimiento especializado y que formalmente abarcan diversos tipos de unidades sígnicas tanto linguísticas como no linguísticas [...]". 5

Em seus estudos, Cabré e Estopà (2005) propõem a classificação das UCEs com base em seis traços característicos básicos:

3 “Tem havido muitas discussões sobre os critérios a serem empregados para distinguir formas compostas de 'frases nominais'. [...] Mas outros autores se baseiam nos critérios semânticos, enfatizando o significado unitário tipicamente associado a compostos (em oposição às frases nominais), ou o fato de que o significado do composto como um todo, normalmente, não pode ser deduzido dos significados dos seus constituintes" (DOWNING, 1977, p.810, tradução nossa).

4 "[...] dois ou mais substantivos acrescidos de adjetivos necessários (e com menos frequência verbos e advérbios) que juntos formam um único conceito, ou seja, o todo expressa a ideia de um 'único substantivo'." (TRIMBLE, 1985, p.130, tradução nossa).

5 " [...] unidades que veiculam conhecimento especializado e que formalmente abraçam diversos tipos de unidades de significação, tanto linguísticas quanto não linguísticas." (ESTOPÀ, 1999, p.25). 
* sistema a que pertencem: linguagem natural ou outras linguagens;

* estrutura: unidades morfológicas (-itis, -genia, apo-); unidades monoléxicas (célula, clonar); unidades sintagmáticas (poliléxicas - alteración cromosómica e fraseológicas - responder a un antígeno); unidades oracionais (cepa obtenida por ingeniería genética);

* categoria gramatical: nominal (cultivo hidropônico); adjetiva (medioambientalmente negativo); verbal (administrar penicilina); adverbial (por via oral);

* classe conceitual (semântica): entidades (célula); eventos (ação ou processoaislamiento del virus, codificar); propriedades (alcalinidad); relações (administrar);

* coesão interna: lexicalizadas ou não lexicalizadas;

* papel linguístico-conceitual que exercem no discurso especializado: rasgo nodo ou rasgo relación.

Tendo em vista a classificação de Cabré e Estopà (2005), descrevemos a seguir alguns aspectos formais relativos à estrutura das UEPNs para, mais adiante, tratarmos de elementos concernentes a sua classe conceitual.

Biber et al. (1999)7 e Celce-Murcia e Larsen-Freeman (1999) ${ }^{8}$ chamam as unidades poliléxicas nominais de noun phrases. As unidades que apresentam mais de um pré-modificador são referidas por Biber et al. (1999, p.596) como noun phrases with multiple premodifiers. ${ }^{9}$ Ambas são descritas como unidades que apresentam quatro componentes principais: determinante + pré-modificador + substantivo $^{10}$ + pós-modificador. O Quadro 2 apresenta alguns exemplos dessas unidades.

6 Cabré e Estopà (2005, p.22) explicam o sentido dos termos rasgo nodo e rasgo relación da seguinte maneira: "De acuerdo con este criterio, las UCE que forman parte de las estructuras conceptuales pueden describirse en forma de conjuntos de rasgos: el rasgo nodo y el rasgo relación. Así tendremos las siguientes combinaciones pertinentes para la representación cognitiva del conocimiento especializado: [+nodo-relación] gen, clon; [+nodo+relación] clonación, cruce. Los nodos poseen 'pesos' conceptuales distintos según su mayor proximidad o alejamiento del nodo central. Cuanto más cercanos al nodo central, mayor peso conceptual; cuanto más distantes, menor peso conceptual."

7 Biber et al. são autores da The Longman Grammar of Spoken and Written English, uma gramática baseada na análise de um corpus de 40 milhões de palavras distribuídas em textos de quatro diferentes registros: textos de ficção, jornalísticos, acadêmicos e transcrição de conversas.

8 Celce-Murcia e Larsen-Freeman (1999) são autoras do The Grammar Book, um livro destinado a professores de ESL/EFL sobre a gramática da língua inglesa. Esse livro, no entanto, não é baseado em corpus.

9 "Frases nominais com pré-modificadores múltiplos" (BIBER et al., 1999, p.596, tradução nossa).

10 Head noun em Biber et al. (1999). 
Quadro 2 - Exemplos de noun phrases ${ }^{11}$

\begin{tabular}{|c|c|c|c|c|}
\hline \multicolumn{5}{|c|}{ A ESTRUTURA DAS UEPNs } \\
\hline & Determinante & Pré-modificador & Substantivo & Pós-modificador \\
\hline 1 & the & [black] [leather] & box & $\varnothing^{12}$ \\
\hline 2 & all the other & beautiful & girls & $\varnothing$ \\
\hline 3 & $a$ & $\varnothing$ & man & of honor \\
\hline 4 & $a$ & special & project & $\varnothing$ \\
\hline 5 & $\varnothing$ & written & reasons & $\varnothing$ \\
\hline 6 & $\varnothing$ & detecting & devices & $\varnothing$ \\
\hline 7 & both & police & reports & $\varnothing$ \\
\hline 8 & $\varnothing$ & [grained] [alluvial] & material & $\varnothing$ \\
\hline 9 & $\varnothing$ & [unusually thick] [naturally-coloured] & cardigan & $\varnothing$ \\
\hline 10 & $\varnothing$ & [formerly self-Sufficient] [rural] [feudal] & economy & $\varnothing$ \\
\hline
\end{tabular}

Fonte: Biber et al. (1999, p.596).

Os determinantes, segundo Celce-Murcia e Larsen-Freeman (1999), dividemse em três categorias: (i) os pré-determinantes, palavras como all e both; (ii) os determinantes centrais, ${ }_{13}^{13}$ como artigos (the, a), demonstrativos (this, that) e possessivos (my, his); e (iii) os pós-determinantes, como quantificadores (three) e termos de referência comparativa (other). Segundo as autoras, o número máximo de determinantes que a língua inglesa parece aceitar é três (como no exemplo 2, do Quadro 2). Apesar de não modificarem a base nominal, os determinantes têm uma função muito importante na tessitura do texto, na medida em que indicam o início de uma nova unidade.

Segundo Biber et al. (1999, p.596), os pré-modificadores são, fundamentalmente, adjetivos (como special, internal - exemplo 4), particípios (como written, hidden, detecting - exemplos 5 e 6) e substantivos (bus, police - exemplo 7); os adjetivos representam a categoria mais comum de pré-modificadores em todos os registros, seguidos da categoria dos substantivos.

\footnotetext{
11 Conforme nomenclatura de Biber et al. (1999).

12 Para cada padrão sugerido por Biber et al. (1999), incluímos um exemplo de nosso corpus de estudo, que identificamos como NC.

13 Core determiners para Celce-Murcia e Larsen-Freeman (1999).
} 
Ainda segundo Biber et al. (1999, p.597), 70 a 80\% dos premodified noun phrases ${ }^{14}$ contêm apenas um pré-modificador; em torno de $20 \%$ contêm dois prémodificadores; e apenas algo em torno de $2 \%$ tem três ou quatro pré-modificadores (Gráfico 1).

Gráfico 1 - Distribuição de pré-modificadores em quatro diferentes registros (CONV, conversation; FICT, fiction; NEWS, newspaper reportage; ACAD, academic prose)

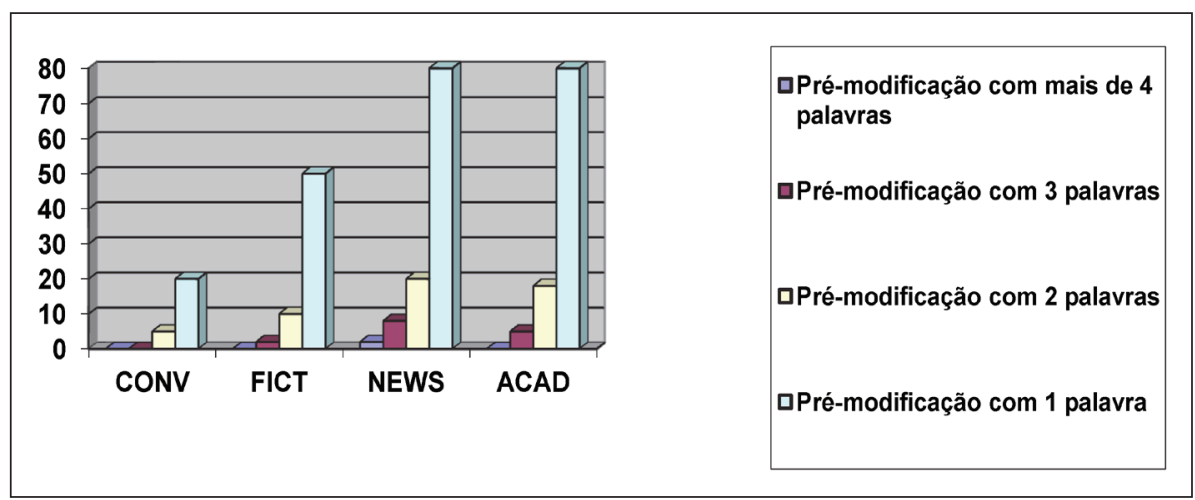

Fonte: Gráfico adaptado de Biber et al. (1999, p.597).

A pré-modificação múltipla permite muitas relações de sentido entre os prémodificadores. Biber et al. (1999, p.598) afirma que "o número de relações lógicas possíveis aumenta dramaticamente com cada pré-modificador adicional". No Quadro 2, os noun phrases 1, 8, 9 e 10 exemplificam algumas das relações de sentido possíveis. Os exemplos 1 e 8, segundo Biber et al. (1999), são os mais raros. No caso de pré-modificação múltipla, os autores afirmam serem mais comuns as relações lógicas complexas, como nos exemplos 9 e 10.

A base nominal, ou substantivo, como prefere Biber et al. (1999), é o núcleo da unidade poliléxica. A partir da base nominal, estabelece-se a classe conceitual à qual a unidade pertence. Com relação à classe conceitual, Cabré e Estopà (2005, p.11) sugerem a classificação das unidades em quatro grupos: entidades, eventos, propriedades e relações. Tal classificação é muito semelhante à apresentada por Sager, Dungworth e McDonald (1980, p.268), ${ }^{15}$ que usam os termos objetos, propriedades, processos e operações; e por Kageura (2002), ${ }^{16}$ que utiliza as

14 "Frases nominais pré-modificadas" (BIBER et al., 1999, p.597, tradução nossa).

15 Sager (1993, p.52) distingue, em um nível mais amplo, quatro grupos de conceitos: entidades, atividades (processos, operações e ações), qualidades e relações.

16 Kageura (2002, p.64) afirma que algumas das categorias mais utilizadas são: entidades, eventos, atributos e relações. 
categorias entity (material, representational, abstract, classificatory), activity (processes, operations, events), quality (properties) e relations.

Neste trabalho, as UEPNs, a partir de suas bases nominais, são classificadas conforme as categorias sugeridas por Sager, Dungworth e McDonald. (1980). Com relação ao núcleo dos compostos presentes nos textos da ciência e tecnologia, Sager, Dungworth e McDonald (1980) afirmam que podem ser divididos em três grupos principais de acordo com o que designam:

- objetos (substâncias, materiais, produtos, aparatos) - o grupo mais numeroso e que apresenta a maior variedade de relações entre determinantes e núcleos;

- propriedades - frequentemente formados pelo determinante especificando o conceito ao qual o property term ${ }^{17}$ está relacionado;

- processos e operações - geralmente formados a partir de substantivos deverbais (dust collection) ou substantivos verbais (metal working).

No Quadro 3 apresentamos alguns exemplos de Sager, Dungworth e McDonald (1980) e também de bases nominais de UEPNs de nosso corpus de estudo, classificadas a partir das categorias de Sager, Dungworth e McDonald (1980).

Quadro 3 - Categorias de bases nominais conforme Sager, Dungwort e McDonald (1980)

\begin{tabular}{|l|l|}
\hline \multicolumn{2}{|c|}{$\begin{array}{c}\text { CATEGORIAS DE SAGER, DUNGWORTH } \\
\text { E MCDONALD (1980) }\end{array}$} \\
\hline \multicolumn{2}{|c|}{ Objetos } \\
\hline $\begin{array}{l}\text { ring NUT Processos e operações } \\
\text { fume EXTRACTOR }\end{array}$ & $\begin{array}{l}\text { bleed VALVE } \\
\text { anti-ice SYSTEM }\end{array}$ \\
\hline \multicolumn{2}{|c|}{ Propriedades } \\
\hline $\begin{array}{l}\text { dust COLLECTION } \\
\text { temperature CONTROL }\end{array}$ & $\begin{array}{l}\text { aborted TAKEOFF } \\
\text { emergency LANDING }\end{array}$ \\
\hline \multicolumn{2}{|c|}{ light BRIGHTNESS } \\
\hline $\begin{array}{l}\text { thrust FORCE } \\
\text { speed RATIO }\end{array}$ \\
\hline
\end{tabular}

Fonte: Elaboração própria.

17 Termo que designa a propriedade. 
Além das categorias conceituais estabelecidas por Sager, Dungworth e McDonald (1980), criamos duas subcategorias da categoria objetos, apresentadas no Quadro 4, juntamente com alguns exemplos de nosso corpus.

Quadro 4 - Subcategorias de bases nominais sugeridas neste trabalho

\begin{tabular}{|l|}
\hline \multicolumn{1}{|c|}{ SUBCATEGORIAS SUGERIDAS } \\
\hline \multicolumn{1}{|c|}{ Informações } \\
\hline $\begin{array}{l}\text { landing SPEED } \\
\text { cruise ALTITUDE }\end{array}$ \\
\hline \multicolumn{1}{|c|}{ Fontes de informação } \\
\hline emergency CHECKLIST
\end{tabular}

Fonte: Elaboração própria.

A primeira subcategoria sugerida é relativa a informações ou valores referentes à operação da aeronave (temperatura, velocidade, sinal, perfil). Sendo manuais de operações, sua intenção principal é diretiva, ou seja, dar instruções de como operar a aeronave. Para tanto, dados como temperatura, altitude, atitude, velocidade, entre tantos outros, são de grande importância, constituindo grande parte do conteúdo do texto especializado. Da mesma forma, a busca pela informação é feita em documentos e instrumentos específicos e em número equivalente à quantidade de informação necessária à operação da aeronave. Assim, justifica-se a segunda subcategoria sugerida, relativa a fontes de informação (manuais, instrumentos, listas, bancos de dados). Durante a análise, as unidades pertencentes a essas subcategorias serão observadas de forma independente e não como subdivisões da categoria objetos.

Desse modo, discutidos os aspectos denominativos, formais e semânticos relativos às UEPNs, caracterizamos as unidades que constituem nosso objeto de estudo como linguísticas quanto à sua natureza (pertencem à língua natural), poliléxicas quanto à sua estrutura (têm mais de um elemento constituinte) e nominais quanto à categoria gramatical (têm como base um substantivo). Quanto a sua classe conceitual, dividem-se nas categorias "objetos", "propriedades", "processos/operações", e nas subcategorias "informações" e "fontes de informação". No que diz respeito à coesão interna (o quão estáveis as unidades são), em sua maioria são não lexicalizadas (composicionais ou transparentes), ${ }^{18} \mathrm{em}$ oposição a uma minoria de unidades lexicalizadas (não composicionais ou opacas).

18 Girju et al. (2005, p.481), no âmbito da linguística computacional, apresentam o termo lexicalized como sinônimo de non-compositional, afirmando que os mesmos são compostos nos quais the meaning is a matter of 
Nosso estudo converge para as UEPNs retiradas de textos em inglês escritos para descrever o funcionamento e a utilização de aeronaves de grande porte usadas comercialmente no Brasil, em manuais de operação aeronáutica. Essas UEPNs, muito frequentes nesses textos, apresentam três traços característicos básicos: (i) representam conceitos especializados da área de operações aeronáuticas; (ii) possuem mais de um elemento constituinte; e (iii) têm como base um substantivo. Essas unidades, portanto, são sintagmas nominais definidos ou indefinidos, com pré-modificadores e uma base ou núcleo nominal. Nosso foco - unidades com três ou mais pré-modificadores - justifica-se por serem estas as de interpretação mais difícil para nossos alunos de cursos de ESP para aviação. A seguir alguns exemplos dessas unidades:

- overhead door caution annunciator panel:19

- aluminum and fiberglass honeycomb-core material; 20

- forward and aft electronic control panel lights brightness, ${ }^{21}$

- STROBE \& STEADY red and green wing tip position lights. ${ }^{22}$

Tal como se procurou mostrar, não há uma unanimidade denominativa no que diz respeito às unidades acima descritas. Da mesma forma, seus aspectos constitutivos também são abordados de forma variável por diferentes autores.

\section{A dificuldade em interpretar as UEPNs}

O uso de múltiplos pré-modificadores antes de uma base nominal é certamente uma forma bastante eficiente de compactar muitas informações em um número reduzido de palavras. Tal prática, muito frequente em textos das áreas técnicas e científicas, representa um fardo muito grande aos leitores e ouvintes, uma vez que as relações lógicas entre os constituintes nem sempre ficam claras. Essa dificuldade aumenta em nosso contexto comunicativo especializado, onde quem lê, além de ser um não especialista, é um leitor secundário, que não possui

convention ("soap opera") (o significado é uma questão de convenção) (novela). Os compositional compounds são definidos pelos autores como those whose meaning can be derived from the meaning of the constituent nouns ("door knob") (aqueles cujo significado pode ser derivado do significado dos substantivos constituintes) (maçaneta).

19 Tradução nossa: "o painel indicador de cuidado acima da porta".

20 Tradução nossa: "um material com núcleo em forma de favo, de alumínio e fibra de vidro".

21 Tradução nossa: "o brilho das luzes do painel de controle dianteiro e traseiro de eletrônicos".

22 Tradução nossa: "as luzes de posição, estroboscópicas e fixas, verdes e vermelhas nas pontas das asas". 
informação pragmática ${ }^{23}$ ou conhecimento especializado suficientes para dar conta da complexidade da unidade.

Fabre (1996) afirma que a interpretação de compostos nominais consiste em recuperar as relações predicativas existentes entre os constituintes. O fato de a unidade não apresentar qualquer indicação dessas relações em sua estrutura só dificulta sua interpretação. Muitos modelos foram desenvolvidos no sentido de tentar facilitar essa análise. Especificamente na área da linguística computacional, Fabre (1996, p.364) divide tais sistemas em domain-dependent systems e domainindependent systems. ${ }^{24}$ Os primeiros dizem respeito a regras de interpretação inferidas a partir da observação de padrões semânticos específicos, como no trabalho desenvolvido por Rosario e Hearst (2001) no âmbito da Medicina. O segundo grupo é construído para dar conta de quaisquer padrões de interpretação, no âmbito da língua geral, como em Finin (1980).

Aprofundando essa questão, apresentamos a seguir uma revisão da literatura com dois objetivos específicos: (i) trazer algumas colocações clássicas sobre a interpretação de compostos nominais apresentadas por Downing (1977) e (ii) mostrar de que forma a interpretação dos compostos nominais tem sido tratada em textos especializados (fundamentalmente de áreas técnicas e da aviação), salientando as soluções encontradas a partir de diferentes posicionamentos teóricos, como o da Linguística Computacional (LEHRBERGER, 1982), o da Language for Special Purposes (LSP)/ESP (TRIMBLE, 1985; SHAWCROSS, 1992a, 1992b) e o da Terminologia (SAGER; DUNGWORTH; McDONALD, 1980). ${ }^{25}$

\section{Downing (1977)}

Em seu estudo, Downing (1977) busca entender o processo de criação e interpretação de compostos nominais não lexicalizados (novel noun+noun compounds ${ }^{26}$ a partir das relações semânticas (semantic relationships) ${ }^{27}$ que se estabelecem entre os elementos constituintes dessas unidades nominais. Segundo Downing (1977), estudos anteriores ao seu pressupunham que as relações sintáticas e semânticas de várias classes de compostos eram finitas em número

23 Dik $(1989,1997)$ chama de informação pragmática o conjunto de conhecimentos, crenças, presunções e opiniões que medeia a comunicação.

24 "[...] sistemas dependentes de domínio e sistemas independentes de domínio" (FABRE, 1996, p.364, tradução nossa).

25 Sager, Dungworth e McDonald (1980), na nossa opinião, encontram-se na interface entre Terminologia e ESP.

26 Denominação utilizada por Downing (1977).

27 Optamos por manter a terminologia predominante nas obras referidas sobre o tema ainda que não acreditemos que o termo relação represente com exatidão o processo que se estabelece entre o modificador e a base nominal. 
e passíveis de serem descobertas pela consideração de um corpus de formas lexicalizadas de uma língua. Os estudos dessa autora "[... . reflect tendencies for compounds to be based on permanent, non-predictable relationships of varying semantic types, depending on the nature of the entity being denoted [...]" (DOWNING, 1977, p.841). ${ }^{28}$ Assim, o trabalho de Downing (1977) mostra que a lista de relações possíveis entre os compostos não é absoluta, tampouco finita. Ainda assim, a autora afirma haver um considerável grau de sobreposição entre as listas de relações propostas por vários autores e aponta uma lista de relações mais comuns, que se encontram descritas no Quadro 5.

Quadro 5 - Relações semânticas sugeridas por Downing (1977)

\begin{tabular}{|c|l|l|}
\hline \multicolumn{1}{|c|}{$\begin{array}{c}\text { Tipo de relação } \\
\text { semântica }\end{array}$} & Exemplo \\
\hline $\mathbf{1}$ & $\begin{array}{l}\text { Whole-part } \\
\text { (Todo-parte) }\end{array}$ & Duck foot (o pé é uma parte do todo que é o pato). ${ }^{29}$ \\
\hline $\mathbf{2}$ & $\begin{array}{l}\text { Half-half } \\
\text { (Metade-metade) }\end{array}$ & Giraffe-CoW30 (dois referentes equivalentes). \\
\hline $\mathbf{3}$ & $\begin{array}{l}\text { Part-whole } \\
\text { (Parte-todo) }\end{array}$ & $\begin{array}{l}\text { Pendulum clock (o relógio é o todo e o pêndulo uma de } \\
\text { suas partes). }\end{array}$ \\
\hline $\mathbf{4}$ & $\begin{array}{l}\text { Composition } \\
\text { (Composição) }\end{array}$ & $\begin{array}{l}\text { Stone furniture (uma mobília feita de um determinado } \\
\text { material, no caso pedra). }\end{array}$ \\
\hline $\mathbf{5}$ & $\begin{array}{l}\text { Comparison } \\
\text { (Comparação) }\end{array}$ & Pumpkin bus (o ônibus que parece uma abóbora) \\
\hline $\mathbf{6}$ & $\begin{array}{l}\text { Time } \\
\text { (Tempo) }\end{array}$ & $\begin{array}{l}\text { Summer dust (a poeira de uma época do ano, no caso, do } \\
\text { verão). }\end{array}$ \\
\hline $\mathbf{7}$ & $\begin{array}{l}\text { Place } \\
\text { (Lugar) }\end{array}$ & $\begin{array}{l}\text { Eastern Oregon meal (a refeição do local chamado Eastern } \\
\text { Oregon). }\end{array}$ \\
\hline $\mathbf{8}$ & $\begin{array}{l}\text { Source } \\
\text { (Origem) }\end{array}$ & Vulture shit (o excremento que vem do urubu). \\
\hline $\mathbf{9}$ & $\begin{array}{l}\text { Product } \\
\text { (Produto) }\end{array}$ & Honey glands (as glândulas que produzem mel). \\
\hline
\end{tabular}

28 “[...] refletem tendências dos compostos com base em relações permanentes e não previsíveis de tipos semânticos em variação, dependendo da natureza da entidade a ser denotada [...]" (DOWNING, 1977, p.841, tradução nossa).

29 Ao invés de traduzirmos os exemplos de Downing, preferimos explicá-los a partir do tipo de relação que representam. As explicações, portanto, são nossas e os exemplos são de Downing (1977).

30 Giraffe-cows são as mamães-girafa que ficam cuidando das crias enquanto o resto do bando vai buscar alimento. Disponível em: <www.spfdbus.com/JessZoo/aboutgiraffes.htm>. Acesso em: 20 mar. 2008. 


\begin{tabular}{|l|l|l|}
\hline \multicolumn{1}{|c|}{$\begin{array}{c}\text { Tipo de relação } \\
\text { semântica }\end{array}$} & Exemplo \\
\hline $\mathbf{1 0}$ & $\begin{array}{l}\text { User } \\
\text { (Usuário) }\end{array}$ & Flee wheel barrow (carrinho de mão daqueles que fogem). \\
\hline $\mathbf{1 1}$ & $\begin{array}{l}\text { Purpose } \\
\text { (Objetivo) }\end{array}$ & Hedge hatchet (machadinha para aparar a cerca viva). \\
\hline $\mathbf{1 2}$ & $\begin{array}{l}\text { Occupation } \\
\text { (Ocupação) }\end{array}$ & Coffee man (o homem que se ocupa de fazer o café). \\
\hline
\end{tabular}

Fonte: Criado com base em Downing (1977, p.828).

Downing (1977) também ressalta a importância da classe semântica da base nominal, que denomina de head noun, na determinação das relações semânticas estabelecidas com tal base. Para comprovar esse fato, a autora divide os compostos utilizados em sua pesquisa em cinco grupos - human, animal, plant, natural object e synthetic object ${ }^{31}$ - conforme a classe semântica de suas bases, e lista as relações estabelecidas com cada uma das categorias. O Quadro 6 mostra o resultado obtido por Downing (1977) nas diferentes tarefas do seu estudo (Attested, Naming, CFI, Ranking). ${ }^{32}$

Quadro 6 - Relações semânticas mais frequentes por categoria de base nominal ${ }^{33}$

\begin{tabular}{|c|l|c|c|c|}
\hline & \multicolumn{1}{|c|}{ Attested } & Naming & \multicolumn{1}{c|}{ CFI } & Ranking \\
\hline \multirow{2}{*}{$\begin{array}{c}\text { Humans } \\
\text { (humanos) }\end{array}$} & PLACE & $\varnothing$ & $\begin{array}{l}\text { OCCUPATION, } \\
\text { HALF/HALF }\end{array}$ & $\varnothing$ \\
\cline { 2 - 5 } & Occupation & & & \\
\cline { 2 - 5 } & Half/half & & & \\
\cline { 2 - 5 } & Comparison & & & \\
\hline
\end{tabular}

31 Downing (1977) apresenta os seguintes exemplos de compostos classificados de acordo com suas bases nominais: police demonstrators, women officers, negro woman (humans); giraffe bird, Salt Creek coyotes (animals); trumpet plant, Texas roadside flowers (plants); granite outcroppings, cow hair, Montana beach (natural objects); banana fork (synthetic object).

32 A pesquisa de Downing (1977) foi estruturada a partir de um número de tarefas experimentais (Attested, Naming, CFI, Ranking), nas quais os sujeitos foram solicitados a interpretar e criar novel compounds (compostos novos).

33 Conforme Downing (1977), relações grafadas com letras maiúsculas em cada categoria parecem ser as de maior relevância classificatória, fato refletido na frequência com que aparecem nas formas compostas. 


\begin{tabular}{|c|c|c|c|c|}
\hline & Attested & Naming & CFI & Ranking \\
\hline \multirow[t]{3}{*}{$\begin{array}{l}\text { Animals } \\
\text { (animais) }\end{array}$} & $\begin{array}{l}\text { PLACE, HALF/ } \\
\text { HALF }\end{array}$ & COMPARISON & PURPOSE & $\varnothing$ \\
\hline & Comparison & Part/whole & $\begin{array}{l}\text { Comparison, } \\
\text { Part/whole }\end{array}$ & \\
\hline & Part/whole, time & Purpose, half/half & & \\
\hline \multirow[t]{2}{*}{$\begin{array}{c}\text { Plants } \\
\text { (plantas) }\end{array}$} & TIME, PLACE & COMPARISON & $\begin{array}{l}\text { HALF/HALF, } \\
\text { PART/WHOLE, } \\
\text { COMPARISON, } \\
\text { PURPOSE }\end{array}$ & $\varnothing$ \\
\hline & & Part/whole, user & & \\
\hline \multirow{6}{*}{$\begin{array}{c}\text { Natural } \\
\text { objects } \\
\text { (objetos } \\
\text { naturais) }\end{array}$} & COMPOSITION & $\varnothing$ & SOURCE & $\begin{array}{l}\text { COMPARISON, } \\
\text { PLACE }\end{array}$ \\
\hline & Place, time & & Composition & \\
\hline & Source & & Comparison & \\
\hline & Whole/part & & $\begin{array}{l}\text { Place, time, } \\
\text { Purpose }\end{array}$ & \\
\hline & $\begin{array}{l}\text { Part/whole, } \\
\text { product }\end{array}$ & & & \\
\hline & Purpose & & & \\
\hline \multirow{5}{*}{$\begin{array}{c}\text { Synthetic } \\
\text { objects } \\
\text { (objetos } \\
\text { sintéticos) }\end{array}$} & PURPOSE & PURPOSE & PURPOSE & PURPOSE \\
\hline & Composition & Whole/part & Comparison & Composition \\
\hline & Place & Part/whole, user & User, place & $\begin{array}{l}\text { Comparison, } \\
\text { Half/half }\end{array}$ \\
\hline & Source & $\begin{array}{l}\text { Composition, } \\
\text { place }\end{array}$ & Whole/part & \\
\hline & Half/half & Comparison & & \\
\hline
\end{tabular}

Fonte: Downing (1977, p.830).

Conforme o Quadro 6, para cada categoria de base nominal, se estabelece um conjunto de relações semânticas. Se compararmos a categoria HUMANS com a categoria SYNTHETIC OBJECTS, por exemplo, será possível notar que a primeira comporta um número bem menor (4) de relações do que a segunda (10), e que o tipo de relação é diferente. Enquanto para naturally existing entities ${ }^{34}$ (HUMANS, ANIMALS, PLANTS, NATURAL OBJECTS) temos como mais

34 Tradução nossa: "entidades de existência natural". 
relevantes as relações lugar, ocupação, metade-metade, comparação, parte-todo, tempo, composição e origem, para SYNTHETIC OBJECTS temos como relação mais frequente a de objetivo. Isso revela que "[...] naturally existing entities are typically classified, at least in our culture, on the basis of inherent characteristics; but synthetic objects are categorized in terms of the uses to which they may be put [...]" (DOWNING, 1977, p.831). ${ }^{35}$

O estudo de Downing (1977), portanto, aborda dois aspectos muito importantes para nossa pesquisa: em primeiro lugar, o fato das relações semânticas, ainda que infinitas, possuírem certo grau de redundância, nos levando a crer que, ainda que possamos aplicar as relações semânticas da língua geral em um âmbito especializado, há possibilidade de identificarmos relações típicas daquele âmbito. Em segundo lugar, o fato das bases nominais terem um papel determinante no estabelecimento das relações semânticas dos modificadores com a base nos faz imaginar que as categorias de bases nominais de um âmbito especializado apresentem certo número de relações mais recorrentes.

Sager, Dungworth e McDonald (1980) e Sager (1993)

Sager, Dungworth e McDonald (1980, p.265) definem compostos como " [...] he combination of two or more words into a new syntagmatic unit with a new meaning independent of the constituent parts [...]" ${ }^{36}$ Para os autores, o entendimento dos compostos está diretamente relacionado à correta interpretação da função e classe dos elementos que os compõem (SAGER; DUNGWORTH; McDONALD, 1980). Por essa razão, eles ressaltam a importância do núcleo do composto como elemento que determina a categoria à qual o conceito pertence e do determinante como indicador do critério para subdivisão da categoria.

The nucleus of the compound, usually the last element, indicates the category to which the concept belongs, and the determinant indicates the criterion for the subdivision of the category. Thus steam-engine (an engine driven by steam) serves the pattern for diesel engine, jute mill (a mill for the production/processing of jute) provides a pattern for flour mill, cotton mill, etc. (SAGER; DUNGWORTH; McDONALD, 1980, p. 268). ${ }^{37}$

35 “[...] as entidades de existência natural são geralmente classificadas, pelo menos em nossa cultura, a partir de suas características inerentes; ao passo que objetos sintéticos são categorizados em termos dos usos aos quais eles se prestam [...]"(DOWNING, 1977, p.831, tradução nossa).

36 " [...] a combinação de duas ou mais palavras em uma nova unidade sintagmática com um novo significado independente das partes constituintes [...]".(SAGER; DUNGWORTH; McDONALD, 1980, p.265, tradução nossa).

37 "O núcleo do composto, normalmente o último elemento, indica a categoria à qual o conceito pertence, e o determinante indica o critério para a subdivisão da categoria. Portanto, motor a vapor (um motor que funciona a vapor) serve de padrão para motor a diesel, usina de juta (uma usina para produção/processamento da juta) 
O núcleo (base nominal) também exercerá a função de restringir o tipo de determinação (predicação), na medida em que sua natureza estabelecerá o tipo de modificação que irá comportar. Conforme Sager, Dungworth e McDonald (1980, p.268):

Depending on the nature of the nucleus, the determinant can specify in greater detail, indicate a purpose, the means by which an operation is carried out, the object to which a process is applied, or the time, place or other circumstances, which in this way become an integral distinctive feature of the new concept..$^{38}$

A partir de sua classificação dos núcleos dos compostos em objetos, propriedades e processos e operações, Sager, Dungworth e McDonald (1980) sugerem relações semânticas que se estabelecem no âmbito da ciência e tecnologia, conforme apresentado no Quadro 7.

Quadro 7 - Relações semânticas sugeridas por

Sager, Dungworth e McDonald (1980)

\begin{tabular}{|c|c|c|}
\hline & Tipo de relação semântica & Exemplo \\
\hline \multicolumn{3}{|c|}{ Objetos } \\
\hline 1 & O determinante compara o núcleo com outro objeto ${ }^{39}$ & Butterfly nut \\
\hline 2 & $\begin{array}{l}\text { O determinante pode especificar o material do qual o } \\
\text { núcleo é feito de forma a diferenciá-lo ou para indicar } \\
\text { o material que compõe o núcleo. } \\
\text { No âmbito da tecnologia, o composto pode ser } \\
\text { expandido por um particípio passado para indicar a } \\
\text { relação da substância com o objeto. }\end{array}$ & $\begin{array}{l}\text { Rubber band e steel band } \\
\text { Rubber shock-absorber } \\
\text { Lead-covered rubber cable }\end{array}$ \\
\hline 3 & $\begin{array}{l}\text { O determinante pode expressar uma propriedade do } \\
\text { conceito, sob a forma de um adjetivo ou particípio } \\
\text { passado. O adjetivo geralmente especifica a cor, } \\
\text { dimensão, gosto. }\end{array}$ & $\begin{array}{l}\text { Pneumatic drill } \\
\text { Amber light } \\
\text { Fixed gauge }\end{array}$ \\
\hline
\end{tabular}

oferece um padrão para usina de farinha, usina de algodão, etc." (SAGER; DUNGWORTH; McDONALD, 1980, p. 268, tradução nossa).

38 "Dependendo da natureza do núcleo, o determinante pode especificar em maior detalhe, indicar um propósito, os meios pelos quais uma operação é conduzida, o objeto ao qual o processo é aplicado, ou o tempo, local ou outras circunstâncias, as quais, dessa maneira, tornam-se um traço distintivo completo do novo conceito". (SAGER; DUNGWORTH; McDONALD, 1980, p.268, tradução nossa).

39 Quando a similaridade não é muito aparente, um composto mais complexo pode ser necessário (claw-type clamp) (SAGER; DUNGWORTH; MCDONALD et al., 1980, p.269). 


\begin{tabular}{|c|c|c|}
\hline & Tipo de relação semântica & Exemplo \\
\hline 4 & $\begin{array}{l}\text { O determinante especifica o uso que se dá ao núcleo } \\
\text { ou contra ele. }\end{array}$ & $\begin{array}{l}\text { Cutting tool } \\
\text { Anti-ice system }\end{array}$ \\
\hline 5 & $\begin{array}{l}\text { O determinante expressa o produto que geralmente } \\
\text { está associado ao núcleo. }\end{array}$ & Bicycle factory \\
\hline 6 & $\begin{array}{l}\text { O núcleo expressa o instrumento que opera no deter- } \\
\text { minante. }\end{array}$ & Fume extractor \\
\hline 7 & $\begin{array}{l}\text { O determinante pode expressar o modo de operação } \\
\text { do núcleo. }\end{array}$ & Spring-loaded switch \\
\hline 8 & O determinante pode ser o todo e o núcleo a parte. & Wing box \\
\hline \multicolumn{3}{|c|}{ Propriedades } \\
\hline 9 & O determinante geralmente especifica o conceito. & $\begin{array}{l}\text { Input torque } \\
\text { Outside temperature }\end{array}$ \\
\hline \multicolumn{3}{|c|}{ Processos e operações } \\
\hline 10 & $\begin{array}{l}\text { O determinante geralmente especifica o sujeito ou } \\
\text { objeto do núcleo que geralmente corresponde a uma } \\
\text { ação verbal. }\end{array}$ & $\begin{array}{l}\text { Temperature change (a } \\
\text { change of temperature) } \\
\text { Emergency landing }\end{array}$ \\
\hline
\end{tabular}

Fonte: Elaborado pela autora baseado em Sager, Dungworth e McDonald (1980, p.268-271).

Em compostos com três ou mais elementos, os autores sugerem que as relações podem se estabelecer:

- do segundo modificador com a base e do primeiro modificador com ambos $(\mathrm{X}+(\mathrm{Y}+\mathrm{Z}))$ (wing (anti-ice));

- ou dos dois modificadores e de ambos com a base $((\mathrm{X}+\mathrm{Y})+\mathrm{Z})$ ((hexagon-headed) bolt).

Sager, Dungworth e McDonald (1980) e Sager (1993) também sugerem que os compostos múltiplos, na medida em que acompanham o desenvolvimento e reestruturação do conhecimento de determinada área, permitem o desenvolvimento de hierarquias formalmente transparentes e que se constroem pela adição de elementos determinantes (Quadro 8). Como afirma o autor: " [... ] a un nivel más detallado de análisis los distintos campos temáticos requerirán diferentes tipos de subestructuras para poder responder plenamente a la diversidad de tipos de conceptos con los que funcionan." (SAGER, 1993, p.52). ${ }^{40}$

40 “[...] em um nível de análise mais detalhado, os diferentes campos temáticos vão requerer diferentes tipos de subestruturas para poder responder plenamente à diversidade de tipos de conceitos com os quais funcionam." 
Quadro 8 - Hierarquias formalmente transparentes que se constroem pela adição de elementos determinantes

\begin{tabular}{|c|c|c|}
\hline & & character \\
\hline & printable & character \\
\hline Non- & printable & character \\
\hline & alphanumeric & character \\
\hline Form- & feed & character \\
\hline
\end{tabular}

Fonte: Sager, Dungworth e McDonald (1980).

Por fim, Sager, Dungworth e McDonald (1980) afirmam que as unidades nominais de seis ou mais elementos geralmente consistem de agrupamentos de compostos, muitas vezes ligados por hífens. O entendimento dessas unidades geralmente se dá "en el marco de un campo especializado" (SAGER, 1993, p.121), ou seja, ressalta-se a importância do conhecimento especializado no entendimento de compostos tão difíceis de serem interpretados. O processo de agrupar as submodificações dentro de compostos longos é chamado de bracketing (GIRJU et al., 2005; BARKER, 1997; BARKER, 1998). Barker (1997, p.41) define esse processo como "grouping a flat list of three or more words into a binary tree structure" ${ }^{41}$ O referido processo pode ser observado nos exemplos descritos no Quadro 9.

Quadro 9 - Exemplos de long compounds agrupados por bracketing ${ }^{42}$

\begin{tabular}{|c|c|c|}
\hline & PRÉ-MODIFICADOR & BASE NOMINAL \\
\hline 1 & [minimum [strain energy] [twisted-folded] & energy] \\
\hline 2 & [[step-by-step][variable speed] & transmission] \\
\hline 3 & [[extra-rapid-hardening] & cement] \\
\hline 4 & [[simply-supported] [steel & beams] \\
\hline
\end{tabular}

Fonte: Sager, Dungworth e McDonald (1980, p.273).

(SAGER, 1993, p.52, tradução nossa).

41 "[...] agrupar uma lista simples de três ou mais palavras em uma estrutura binária de árvore". (BARKER, 1997, tradução nossa)

42 Exemplos de Sager, Dungworth e McDonald (1980, p.273) e de Sager (1993, p.121). 
Nota-se que, assim como Downing (1977), Sager, Dungworth e McDonald (1980) também ressaltam o papel das bases nominais como elementos que restringem a predicação comportada pelas unidades compostas. Além disso, Sager, Dungworth e McDonald (1980) e Sager (1993) chamam a atenção para a forma pela qual os modificadores, em unidades longas, podem se agrupar em submodificações antes da base ou com ela, em um processo chamado por outros autores de bracketing (GIRJU et al., 2005; BARKER, 1997; BARKER, 1998).

\section{Lehrberger (1982)}

Lehrberger (1982) afirma que um dos traços principais do corpus estudado por ele foram as longas sequências de substantivos, ou substantivos e adjetivos, dentro de grupos nominais, os quais ele chamou de empilages (empilhamento) e definiu como "the segment of such a noun phrase from the first adjective or noun to the last noun." ${ }^{3}$ Ele afirma ter identificado no corpus de manuais de manutenção aeronáutica, referente ao sistema hidráulico, 4.400 empilages, algumas com até nove modificadores, como é possível observar nos exemplos a seguir (LEHRBERGER, 1982, p.92):

- fan nozzle discharge static pressure water manometer;

- external hydraulic power ground test quick-disconnect fittings;

- fuselage aft section flight control and utility hydraulic system filter elements.

De acordo com o autor, os problemas envolvidos em fazer o parsing de unidades tão longas são semelhantes ao problema enfrentado por linguistas para explicar a formação de compostos nominais. Lehrberger (1982, p.93) cita Downing (1977) e Levi (1978) ao sugerir que a interpretação das empilages deveria partir de uma matriz de relações semânticas. Ele ressalta que a referida lista pode ser suficiente para analisar as empilages do âmbito de especialidade, mas que ele não pode afirmar que o mesmo aconteceria na língua geral:

This list of semantic/syntactic relations may turn out to be sufficient for analysis of empilages in the sublanguage under investigation, but no claim is made for the whole language. [...] success in finding a finite set (at least small enough to be useful in automatic parsing) may depend on just such limitations as are encountered in a sublanguage. (LEHRBERGER, 1982, p.93). ${ }^{44}$

43 "[...] a divisão de uma frase nominal é do primeiro adjetivo ou substantivo para o último substantivo."(LEHRBERGER, 1982, p.92, tradução nossa).

44 "Esta lista de relações semânticas/sintáticas pode acabar sendo suficiente para a análise das empilages na sublíngua sob investigação, mas nenhuma reivindicação é feita para a língua como um todo. [...] o sucesso na procura por um conjunto finito (que seja ao menos suficientemente pequeno para ser útil na análise automática) 
Por fim, Lehrberger (1982, p.93) menciona que em seu estudo identificou aproximadamente 50 relações semânticas como half, whole-part, place, subject e object. As demais relações, infelizmente, não são mencionadas pelo autor.

A sugestão de Lehrberger (1982), para a interpretação das empilages, portanto, está intimamente relacionada ao estabelecimento das relações semânticas que ocorrem entre os elementos constituintes da unidade.

\section{Trimble (1985)}

Trimble (1985) afirma que, muitas vezes, o entendimento do que ele chama de complex compounds é quase impossível mesmo para os falantes nativos. Como forma de facilitar o entendimento e a construção dessas unidades, ele sugere oito regras que "[...] can also be misleading as it suggests that most compounds can be understood by simply applying the 'rules' [...]"45 (TRIMBLE, 1985, p.30). As regras de Trimble (1985) mais estreitamente relacionadas à interpretação dos compostos são:

1) Compounds are usually formed from prepositional phrases or relative clauses and many can be back-formed into one or the other of these. ${ }^{46}$ Ex.: travel book $=$ livro sobre viagem ${ }^{47}$

2) The simplest types of compounds are those formed from prepositional phrases with "of". 48

Ex.: a desk drawer = uma gaveta de escrivaninha

3) Prepositional phrases with 'for' are also the basis for compounds. ${ }^{49}$ Ex.: a tin opener = a device "for" opening tins = um dispositivo para abrir latas

pode depender exatamente das mesmas limitações encontradas em uma sublíngua." (LEHRBERGER, 1982, p.93, tradução nossa).

45 “[...] podem levar a um entendimento errôneo, na medida em que sugerem que a maior parte dos compostos pode ser entendida simplesmente aplicando-se as 'regras'[...]" (TRIMBLE, 1985, p.30, tradução nossa).

46 Tradução nossa: "Os compostos são geralmente formados a partir de frases preposicionais ou relativas, e podem ser transformados de volta em uma destas estruturas".

47 Ainda que, como o autor mesmo exemplifica, um telephone book não seja um livro sobre telefones.

48 Tradução nossa: "Os tipos mais simples de compostos são aqueles formados a partir de frases preposicionais com 'de'".

49 Tradução nossa: "Frases preposicionais com 'para' também são a base para compostos". 
4) Some compounds come from relative clauses. ${ }^{50}$

Ex.: a shoe store = uma loja onde sapatos são vendidos

5) Compounds that lend themselves to translation can be translated in several ways: ${ }^{51}$

Ex.: a boat trip = uma viagem por/em um barco

laboratory equipment = equipamento usado em um laboratório

mathematics problem = um problema em matemática

As sugestões de Trimble (1985), portanto, estão fundamentadas em dois processos básicos: o primeiro, chamado por ele de back-formation; e o segundo, de translation. Um e outro dizem respeito à capacidade de redizer o que foi dito no composto, ou seja, de parafrasear o composto. Para aqueles compostos que Trimble (1985, p.133) chama de mais complexos (more complex) e muito complexos (very complex), ${ }^{52}$ ele sugere que os mesmos sejam explicados por seus autores, ou que, em se tratando de um contexto de sala de aula, os alunos elaborem listas que serão explicadas pelos professores das áreas técnicas ou levadas pelos professores de língua inglesa a esses profissionais e depois trazidas para a sala de ESP para serem trabalhadas e entendidas. De qualquer forma, esses processos não propiciam aos alunos a total capacidade de lidar com compostos mais complexos que por ventura se apresentem a eles na sua futura prática profissional.

Shawcross (1992a e 1992b)

Shawcross (1992a) chama as unidades compostas de noun clusters, definidas por ele simplesmente como uma chain of words (corrente de palavras). Segundo ele, essas unidades devem ser entendidas a partir do princípio de que a última palavra dessa corrente é a key word (palavra-chave) e as palavras anteriores são os qualifiers (modificadores), que qualificam a palavra-chave com informação específica.

50 Tradução nossa: "Alguns compostos vêm de frases relativas".

51 Tradução nossa: "Compostos que permitem a tradução podem ser traduzidos de várias formas".

52 Tal definição se dá em função do tamanho e da dificuldade de realizar a paráfrase. É interessante notar que muitos dos exemplos que Trimble (1985) apresenta de compostos mais complexos e muito complexos são retirados da aviação: "Full swivel steerable non-retracting tail wheel overhaul", "Aisle-seat speech-interference level". 
O autor sugere algumas relações semânticas, estabelecidas em relação à base nominal, no contexto da aviação, conforme descrito no Quadro 10.

Quadro 10 - Relações semânticas de unidades do âmbito da aviação sugeridas por Shawcross (1992a)

\begin{tabular}{|l|l|l|l|l|}
\hline LOCATION & $\begin{array}{l}\text { SYSTEM/ } \\
\text { FUNCTION }\end{array}$ & $\begin{array}{l}\text { ASSEMBLY/ } \\
\text { FUNCTION }\end{array}$ & SUB-ASSEMBLY & COMPONENT \\
\hline left & engine & mounting & bolt & washer \\
\hline Upper & rudder & servo & drive & rod \\
\hline Nose & gear & ground & safety & pin \\
\hline
\end{tabular}

Fonte: Shawcross (1992a, p.11).

Shawcross (1992a) também afirma que, para que se possa entender o sentido dessas unidades, é preciso ser metódico, analisar o contexto, não traduzir muito literalmente e buscar a realidade da aeronave que subjaz ao texto: "You must be methodical, analyse the context. Your interpretation must be coherent. Don't translate too literally. Find the reality of the aircraft behind the text." (SHAWCROSS, 1992a, p.12)..$^{53}$

Shawcross (1992a), portanto, identifica dentro do âmbito da aviação as seguintes funções/relações semânticas: localização (left, upper, nose), função (mounting) e todo/parte (engine - washer, rudder - rod, gear - pin). A forma como Shawcross (1992a) apresenta a informação, no entanto, não deixa muito claro o que ele entende por assembly e sub-assembly. Ele chama a relação que se estabelece entre o motor e a arruela (engine - washer) de system/component (sistema/componente); nesse caso, a arruela é um componente de um sistema maior que é o motor. Entendido dessa forma, é possível supor que assembly (conjunto) e sub-assembly (subconjunto) sejam parte de um sistema maior, como mostra o Quadro 11.

53 "Você deve ser metódico, analisar o contexto. Sua interpretação deve ser coerente. Não traduza literalmente. Encontre a realidade da aeronave por detrás do texto." (SHAWCROSS, 1992a, p.12, tradução nossa). 
Quadro 11 - Relação de sistema, conjunto, subconjunto e componente

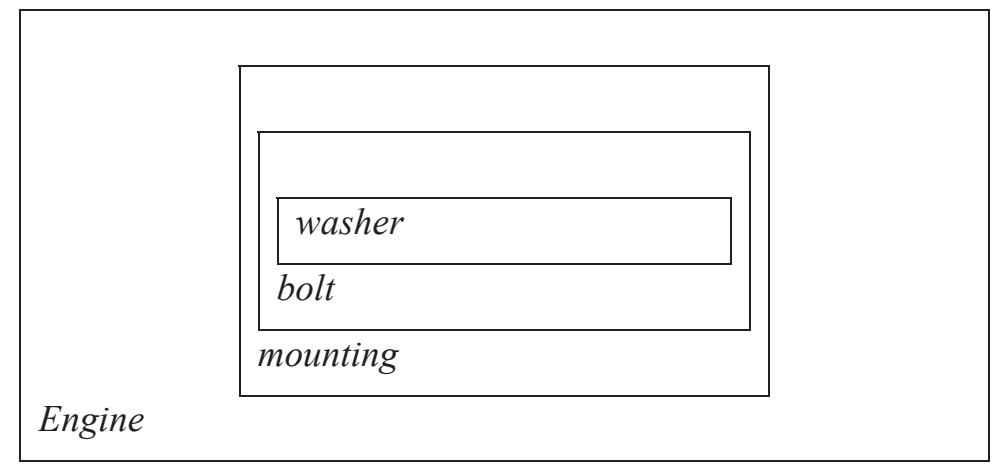

Fonte: Shawcross (1992a, p.52).

Assim, a arruela, entendida como um componente do parafuso, faria parte de um subconjunto ou subsistema de montagem de um sistema maior, o sistema do motor. Ainda que não afirme que as relações estabelecidas nos compostos nominais sejam fundamentalmente as de localização, função e todo/parte, Shawcross (1992a) não cita outras relações.

\section{A interpretação das relações semânticas das UEPNs e sua aplicabilidade no âmbito da aviação}

Ao longo da revisão apresentada, muitos aspectos importantes para o entendimento das relações semânticas das UEPNs foram ressaltados. De todos esses elementos, fatos e considerações, listamos a seguir aqueles que acreditamos serem aplicáveis e suficientes para dar conta das relações intraconceituais que se estabelecem nessas unidades nos textos de aviação:

- o papel do conhecimento especializado como marco para o entendimento das unidades nominais longas;

- o processo de bracketing como auxiliar no estabelecimento das relações de submodificação em compostos longos;

- a construção das hierarquias formais de famílias de compostos longos, no sentido de facilitar a compreensão do processo de criação e estruturação da unidade, tornando as relações semânticas entre os modificadores mais visíveis;

- o fato de as bases nominais terem um papel determinante no estabelecimento das relações semânticas dos modificadores com a base, o que nos faz imaginar que as categorias de bases nominais de um âmbito especializado apresentem um número mais restrito de relações mais frequentes; 
- o estabelecimento de uma matriz de relações semânticas para a correta interpretação das relações de predicação que ocorrem entre os elementos constituintes das unidades nominais longas;

- o fato de as relações semânticas, ainda que infinitas, possuírem certo grau de redundância, nos levando a crer que, ainda que possamos aplicar aquelas da língua geral em um âmbito especializado, há possibilidade de identificarmos relações típicas daquele âmbito.

A partir dessas colocações, procuramos apresentar uma matriz de relações semânticas que pudesse servir de base para a interpretação das UEPNs nos textos dos manuais de aviação. Com base em Downing (1977), que afirma que as relações semânticas propostas por diferentes autores apresentam um considerável grau de sobreposição, buscamos as listas de relações semânticas sugeridas para a língua geral por Levi (1978) e Adams (2001), e as agrupamos por semelhança com as de Downing (1977). Constatada a redundância, ou seja, a repetição da maioria das relações nas três listas, agrupamos as relações semelhantes, eliminando aquelas que eram citadas apenas uma vez. Com esse agrupamento, buscamos criar uma matriz com relações que fossem usuais na língua geral. O Quadro 12 apresenta o resultado de tal sobreposição. Optamos por manter neste quadro o nome dos autores, bem como a denominação e exemplos utilizados por eles.

Quadro 12 - Relações semânticas sugeridas por Downing (1977), Levi (1978) e Adams (2001) agrupadas por semelhança

\begin{tabular}{|c|c|c|c|}
\hline & $\begin{array}{c}\text { Tipo de } \\
\text { relação } \\
\text { semântica }\end{array}$ & Autores & Exemplo \\
\hline 1 & Whole-part & Downing (1977) & $\begin{array}{l}\text { Duck foot (o pé É UMA PARTE DO TODO que é } \\
\text { o pato). }\end{array}$ \\
\hline 2 & Half-half & Downing (1977) & Giraffe-cow (dois objetos com equivalência). \\
\hline 3 & Part-whole & Downing (1977) & $\begin{array}{l}\text { Pendulum clock (o relógio é o todo e o pêndulo } \\
\text { uma de suas partes). }\end{array}$ \\
\hline 20 & Composition & $\begin{array}{l}\text { Adams }(2001, \\
\text { p.83) }\end{array}$ & $\begin{array}{l}\text { Butter mountain (a montanha COMPOSTA DE } \\
\text { manteiga). }\end{array}$ \\
\hline 21 & Material & $\begin{array}{l}\text { Adams } \\
(2001, \text { p.83) }\end{array}$ & Ivory tower (a torre FEITA DO MATERIAL marfim). \\
\hline 4 & Composition & Downing (1977) & $\begin{array}{l}\text { Stone furniture (uma mobília FEITA DE UM } \\
\text { DETERMINADO MATERIAL ... pedra). }\end{array}$ \\
\hline
\end{tabular}




\begin{tabular}{|c|c|c|c|}
\hline & $\begin{array}{c}\text { Tipo de } \\
\text { relação } \\
\text { semântica }\end{array}$ & Autores & Exemplo \\
\hline 6 & Place & Downing (1977) & $\begin{array}{l}\text { Eastern Oregon meal (a refeição DO LOCAL } \\
\text { CHAMADO Eastern Oregon) }\end{array}$ \\
\hline 13 & Location & $\begin{array}{l}\text { Adams } \\
(2001, \text { p.83) } \\
\end{array}$ & $\begin{array}{l}\text { Amusement park (o parque está localizado na } \\
\text { diversão). }{ }^{54}\end{array}$ \\
\hline 10 & Purpose & Downing (1977) & $\begin{array}{l}\text { Hedge hatchet (um tesourão COM O PROPÓSITO } \\
\text { DE aparar uma cerca viva). }\end{array}$ \\
\hline 12 & Function & $\begin{array}{l}\text { Adams } \\
(2001, \text { p.83) } \\
\end{array}$ & $\begin{array}{l}\text { Traffic lights (as luzes QUE TÊM A FUNÇÃO DE } \\
\text { orientar o trânsito). }\end{array}$ \\
\hline 19 & Content & $\begin{array}{l}\text { Adams } \\
(2001, \text { p.83) } \\
\end{array}$ & Cheque book (o livro QUE CONTÉM cheques). \\
\hline 24 & Have & Levi (1978) & Picture book (o livro QUE TEM figuras). \\
\hline 18 & $\begin{array}{l}\text { What } \\
\text { something is } \\
\text { about }\end{array}$ & $\begin{array}{l}\text { Adams } \\
(2001, \text { p.83) }\end{array}$ & Tax law (a lei OUE É SOBRE taxas). \\
\hline 31 & About & Levi (1978) & Tax law (a lei QUE É SOBRE taxas). \\
\hline 30 & From & Levi (1978) & Olive oil (óleo DA azeitona). \\
\hline 15 & Origin/source & $\begin{array}{l}\text { Adams } \\
(2001, \text { p.83) } \\
\end{array}$ & Mountain ash (as cinzas QUE VÊM DA montanha). \\
\hline 7 & Source & Downing (1977) & Vulture shit (o excremento QUE VEM do urubu). \\
\hline 9 & User & Downing (1977) & $\begin{array}{l}\text { Flee wheel barrow (o carrinho de mão USADO } \\
\text { POR pulgas). }\end{array}$ \\
\hline 26 & Use & Levi (1978) & Steam iron (ferro de passar roupa que USA vapor). \\
\hline 14 & Cause & $\begin{array}{l}\text { Adams } \\
(2001, \text { p.83) }\end{array}$ & Horror film (o filme QUE CAUSA horror). \\
\hline 23 & Cause & Levi (1978) & Tear gás (gás que CAUSA lágrimas). \\
\hline 8 & Product & Downing (1977) & $\begin{array}{l}\text { Honey glands (as glândulas QUE PRODUZEM } \\
\text { mel). }\end{array}$ \\
\hline 25 & Make & Levi (1978) & Honey bee (a abelha que FAZ mel). \\
\hline 17 & $\begin{array}{l}\text { Resemblance } \\
\text { (Semelhança) } \\
\end{array}$ & \begin{tabular}{|l|} 
Adams \\
$(2001, p .83)$ \\
\end{tabular} & Bell jar (a jarra QUE É PARECIDA COM um sino). \\
\hline 5 & $\begin{array}{l}\text { Comparison } \\
\text { (Comparação) }\end{array}$ & Downing (1977) & Pumpkin bus (o ônibus que parece uma abóbora). \\
\hline
\end{tabular}

Fonte: Elaboração própria a partir de Downing (1977), Levi (1978) e Adams (2001).

54 A nosso ver, este exemplo trazido por Downing não representa a relação sugerida. 
Em um segundo momento, acrescentamos a esse conjunto de relações aquelas sugeridas por Sager, Dungworth e McDonald (1980) para as áreas técnico-científicas, assim como as apresentadas por Shawcross (1992a) para o âmbito da aviação. Incluímos, em cada categoria, uma pequena descrição e uma pergunta com o propósito de facilitar a identificação das relações durante a análise das UEPNs. Da mesma forma, mantivemos a divisão de relações conforme as categorias de objetos, propriedades e processos e operações sugeridas por Sager, Dungworth e McDonald (1980). O Quadro 13 apresenta a matriz de relações semânticas resultante da sobreposição descrita, a qual sugerimos como base para a interpretação das UEPNs nos textos dos manuais de aviação.

Quadro 13 - Relações semânticas agrupadas por semelhança a partir de Downing (1977), Levi (1978), Sager, Dungworth e McDonald (1980), Shawcross (1992a) e Adams (2001)55

\begin{tabular}{|c|c|c|c|}
\hline & $\begin{array}{l}\text { Tipo de relação } \\
\text { semântica }\end{array}$ & Autores & Exemplo $^{6}$ \\
\hline \multicolumn{4}{|c|}{ Objetos (substâncias, materiais, produtos, aparatos). } \\
\hline 1 & $\begin{array}{l}\text { PARTE-TODO } \\
\text { TODO-PARTE }\end{array}$ & & \\
\hline & \begin{tabular}{|l} 
Whole-part \\
(Todo-parte)
\end{tabular} & Downing (1977) & \multirow{3}{*}{$\begin{array}{l}\text { Door lever (a alavanca É UMA } \\
\text { PARTE DO TODO que é a } \\
\text { porta) } \\
\text { Air conditioning valve (a } \\
\text { válvula É UMA PARTE DO } \\
\text { SISTEMA que é o sistema de } \\
\text { ar condicionado). }\end{array}$} \\
\hline & \begin{tabular}{|l|} 
System-assembly \\
(Sistema-conjunto) \\
Assembly-sub assembly \\
(Conjunto-subconjunto) \\
\end{tabular} & $\begin{array}{l}\text { Shawcross } \\
\text { (1992a) }\end{array}$ & \\
\hline & $\begin{array}{l}\text { O determinante é o todo, e } \\
\text { o núcleo, a parte. }\end{array}$ & $\begin{array}{l}\text { Sager, Dungworth e } \\
\text { McDonald } \\
(1980)\end{array}$ & \\
\hline \multirow[t]{5}{*}{2} & COMPOSIÇÃO & $\begin{array}{l}\text { Que é composto/feito de } \\
\text { Do que é feito(a)/compost }\end{array}$ & a) $\mathrm{o}(\mathrm{a})$ \\
\hline & \begin{tabular}{|l|l} 
Composition \\
(Composição)
\end{tabular} & Adams (2001, p.83) & \multirow{4}{*}{$\begin{array}{l}\text { Aluminum and fiberglass ma- } \\
\text { terial (o material COMPOSTO } \\
\text { DE/FEITO DE UM DETERMI- } \\
\text { NADO MATERIAL alumínio } \\
\text { fibra de vidro). }\end{array}$} \\
\hline & $\begin{array}{l}\text { Material } \\
\text { (Material) }\end{array}$ & $\begin{array}{l}\text { Adams } \\
(2001, \text { p.83) }\end{array}$ & \\
\hline & $\begin{array}{l}\text { Composition } \\
\text { (Composição) }\end{array}$ & Downing (1977) & \\
\hline & $\begin{array}{l}\text { O determinante especifica } \\
\text { o material do qual o núclec } \\
\text { é feito ou indica o material } \\
\text { que compõe o núcleo. }\end{array}$ & $\begin{array}{l}\text { Sager, Dungworth e } \\
\text { McDonald } \\
\text { (1980) }\end{array}$ & \\
\hline
\end{tabular}

55 Todos os exemplos deste quadro foram retirados de nosso corpus de estudo. 


\begin{tabular}{|c|c|c|c|c|}
\hline & \multicolumn{2}{|c|}{$\begin{array}{l}\text { Tipo de relação } \\
\text { semântica }\end{array}$} & Autores & Exemplo $^{6}$ \\
\hline \multirow[t]{4}{*}{3} & LOCALIZAÇÃO & \multicolumn{3}{|c|}{$\begin{array}{l}\text { Que é localizado ou se relaciona a } \\
\text { Onde está localizado(a) o(a) ? ? Ao que se relaciona } \\
\text { ? }\end{array}$} \\
\hline & \multicolumn{2}{|l|}{$\begin{array}{l}\text { Place } \\
\text { (Lugar) }\end{array}$} & Downing (1977) & \multirow{3}{*}{$\begin{array}{l}\text { Center tank (o tanque QUE } \\
\text { ESTÁ LOCALIZADO no } \\
\text { centro). }\end{array}$} \\
\hline & \multicolumn{2}{|l|}{\begin{tabular}{|l}
$\begin{array}{l}\text { Location } \\
\text { (Localização) }\end{array}$ \\
\end{tabular}} & $\begin{array}{l}\text { Adams } \\
\text { (2001, p.83) }\end{array}$ & \\
\hline & \multicolumn{2}{|l|}{$\begin{array}{l}\text { Location } \\
\text { (Localização) }\end{array}$} & $\begin{array}{l}\text { Shawcross } \\
(1992 a)\end{array}$ & \\
\hline \multirow[t]{4}{*}{4} & FUNÇÃO & \multicolumn{3}{|c|}{$\begin{array}{l}\text { Que tem a função/o propósito/o objetivo de } \\
\text { Qual a função/o propósito/o objetivo do(a) }\end{array}$} \\
\hline & \multicolumn{2}{|l|}{$\begin{array}{l}\begin{array}{l}\text { Purpose } \\
\text { (Objetivo) }\end{array} \\
\end{array}$} & Downing (1977) & \multirow{3}{*}{$\begin{array}{l}\text { Logo light (a luz COM O PRO- } \\
\text { PÓSITO DE/ QUE TEM A FUN- } \\
\text { CCÃO DE iluminar a logomarca } \\
\text { da empresa na aeronave). }\end{array}$} \\
\hline & \multicolumn{2}{|l|}{$\begin{array}{l}\begin{array}{l}\text { Function } \\
\text { (Função) }\end{array} \\
\end{array}$} & $\begin{array}{l}\text { Adams } \\
(2001, p .83)\end{array}$ & \\
\hline & \multicolumn{2}{|l|}{$\begin{array}{l}\text { Function } \\
\text { (Função) } \\
\end{array}$} & \begin{tabular}{|l}
$\begin{array}{l}\text { Shawcross } \\
(1992 a)\end{array}$ \\
\end{tabular} & \\
\hline \multirow[t]{3}{*}{5} & CONTEÚDO & \multicolumn{3}{|c|}{$\begin{array}{l}\text { Que contém } \\
\text { O que contém o(a) }\end{array}$} \\
\hline & \multicolumn{2}{|l|}{\begin{tabular}{|l|} 
Content \\
(Conteúdo)
\end{tabular}} & $\begin{array}{l}\text { Adams } \\
\text { (2001, p.83) }\end{array}$ & \multirow{2}{*}{$\begin{array}{l}\text { Cargo compartment (o com- } \\
\text { partimento QUE CONTÉM } \\
\text { carga). }\end{array}$} \\
\hline & \begin{tabular}{|l|}
$\begin{array}{l}\text { Have } \\
\text { (Ter) }\end{array}$ \\
\end{tabular} & & Levi (1978) & \\
\hline \multirow[t]{3}{*}{6} & ASSUNTO & \multicolumn{3}{|c|}{$\begin{array}{l}\text { Que é sobre } \\
\text { Sobre o que é o(a) }\end{array}$} \\
\hline & \multicolumn{2}{|c|}{$\begin{array}{l}\text { What something is about } \\
\text { (Sobre o que é o(a) _ ? }\end{array}$} & $\begin{array}{l}\text { Adams } \\
(2001, p .83)\end{array}$ & \multirow[t]{2}{*}{$\begin{array}{l}\text { Landing procedure (o procedi- } \\
\text { mento QUE É SOBRE o pouso) }\end{array}$} \\
\hline & $\begin{array}{l}\text { About } \\
\text { (Sobre) }\end{array}$ & & Levi (1978) & \\
\hline \multirow[t]{5}{*}{7} & PROCEDÊNCIA & \multicolumn{2}{|c|}{$\begin{array}{l}\text { De onde vem/é o(a) } \\
\text { do(a) ? }\end{array}$} & ? ou Qual o sentido do fluxo \\
\hline & \multicolumn{2}{|l|}{$\begin{array}{l}\begin{array}{l}\text { From } \\
(\mathrm{De})\end{array} \\
\end{array}$} & Levi (1978) & \multirow[t]{4}{*}{$\begin{array}{l}\text { Engine air (ar DO/QUE VEM } \\
\text { DO motor). }\end{array}$} \\
\hline & \multicolumn{2}{|l|}{$\begin{array}{l}\text { Origin/source } \\
\text { (Origem) }\end{array}$} & $\begin{array}{l}\text { Adams } \\
\text { (2001, p.83) }\end{array}$ & \\
\hline & \multicolumn{2}{|l|}{$\begin{array}{l}\text { Source } \\
\text { (Origem) }\end{array}$} & Downing (1977) & \\
\hline & \multicolumn{2}{|c|}{$\begin{array}{l}\text { O determinante expressa } \\
\text { o produto associado ao } \\
\text { núcleo }\end{array}$} & $\begin{array}{l}\text { Sager, Dungworth e } \\
\text { McDonald } \\
\text { (1980) }\end{array}$ & \\
\hline
\end{tabular}




\begin{tabular}{|c|c|c|c|c|}
\hline & \multicolumn{2}{|c|}{$\begin{array}{l}\text { Tipo de relação } \\
\text { semântica }\end{array}$} & Autores & Exemplo $^{6}$ \\
\hline \multirow[t]{4}{*}{8} & USO/USUÁRIO & \multicolumn{3}{|c|}{$\begin{array}{l}\text { Que usa/é usado por } \\
\text { Quem usa o(a) ? }\end{array}$} \\
\hline & \multicolumn{2}{|l|}{$\begin{array}{l}\text { User } \\
\text { (Usuário) }\end{array}$} & Downing (1977) & $\begin{array}{l}\text { Attendant panel (o painel USA- } \\
\text { DO POR comissários). }\end{array}$ \\
\hline & \multicolumn{2}{|l|}{$\begin{array}{l}\text { Use } \\
\text { (Uso) }\end{array}$} & Levi (1978) & $\begin{array}{l}\text { Pressure door (a porta que USA } \\
\text { pressão). }\end{array}$ \\
\hline & \multicolumn{2}{|c|}{$\begin{array}{l}\text { O determinante especifica } \\
\text { o uso que se dá ao núcleo } \\
\text { ou contra ele. }\end{array}$} & $\begin{array}{l}\text { Sager, Dungworth e } \\
\text { McDonald } \\
(1980)\end{array}$ & $\begin{array}{l}\text { Anti-ice system (o sistema } \\
\text { USADO contra o gelo) }\end{array}$ \\
\hline \multirow[t]{3}{*}{9} & FUNCIONAMENTO & \multicolumn{3}{|c|}{$\begin{array}{l}\text { Que funciona/é operado com/a partir de } \\
\text { Como funciona/é operado/é acionada o(a) }\end{array}$} \\
\hline & \multicolumn{2}{|c|}{$\begin{array}{l}\text { How something functions } \\
\text { (Como funciona o(a) _ ?) }\end{array}$} & $\begin{array}{l}\text { Adams } \\
(2001, p .83)\end{array}$ & $\begin{array}{l}\text { Engine driven pump (uma } \\
\text { bomba OUE FUNCIONA COM } \\
\text { O/É ACIONADA PELO motor). }\end{array}$ \\
\hline & \multicolumn{2}{|c|}{$\begin{array}{l}\text { O determinante expressa } \\
\text { o modo de operação do } \\
\text { núcleo }\end{array}$} & $\begin{array}{l}\text { Sager, Dungworth e } \\
\text { McDonald } \\
(1980)\end{array}$ & $\begin{array}{l}\text { Pneumatic valve (uma válvu- } \\
\text { la OUE OPERA/FUNCIONA } \\
\text { pneumaticamente) }\end{array}$ \\
\hline \multirow[t]{3}{*}{10} & OCUPAÇÃO/POSSE & \multicolumn{3}{|c|}{$\begin{array}{l}\text { Que é do/ que se ocupa de } \\
\text { Quem se ocupa do(a) ? ou De quem é o(a) }\end{array}$} \\
\hline & \multicolumn{2}{|l|}{$\begin{array}{l}\text { Occupation } \\
\text { (Ocupação) }\end{array}$} & Downing (1977) & $\begin{array}{l}\text { Flight attendant (o atendente } \\
\text { QUE SE OCUPA DO voo). }\end{array}$ \\
\hline & \multicolumn{2}{|l|}{$\begin{array}{l}\text { Possessor } \\
\text { (Possuidor) }\end{array}$} & $\begin{array}{l}\text { Adams } \\
(2001, p .83)\end{array}$ & $\begin{array}{l}\text { Captain escape strap (a corda } \\
\text { de fuga QUE É DO comandan- } \\
\text { te). }\end{array}$ \\
\hline \multirow[t]{4}{*}{11} & SEMELHANÇA & \multicolumn{3}{|c|}{$\begin{array}{l}\text { Que é parecido com } \\
\text { Com o que é parecido(a) o(a) }\end{array}$} \\
\hline & \multicolumn{2}{|c|}{$\begin{array}{l}\text { O determinante compara o } \\
\text { núcleo com outro objeto }\end{array}$} & $\begin{array}{l}\text { Sager, Dungworth e } \\
\text { McDonald } \\
(1980) \\
\end{array}$ & $\begin{array}{l}\text { Butterfly nut (a porca EM FOR- } \\
\text { MA DE borboleta). }\end{array}$ \\
\hline & \multicolumn{2}{|l|}{$\begin{array}{l}\text { Resemblance } \\
\text { (Semelhança) }\end{array}$} & $\begin{array}{l}\text { Adams } \\
(2001, p .83)\end{array}$ & $\begin{array}{l}\text { Bell jar (a jarra OUE É PARECI- } \\
\text { DA COM um sino). }\end{array}$ \\
\hline & \multicolumn{2}{|l|}{$\begin{array}{l}\text { Comparison } \\
\text { (Comparação) }\end{array}$} & Downing (1977) & $\begin{array}{l}\text { Pumpkin bus (o ônibus QUE } \\
\text { PARECE UMA abóbora). }\end{array}$ \\
\hline \multirow[t]{2}{*}{12} & PROPRIEDADES & \multicolumn{3}{|c|}{$\begin{array}{l}\text { Que descreve uma propriedade } \\
\text { Qual é a propriedade do(a) }\end{array}$} \\
\hline & \multicolumn{2}{|c|}{$\begin{array}{l}\text { O determinante expressa } \\
\text { uma propriedade sob a } \\
\text { forma de adjetivo (cor, } \\
\text { dimensão, gosto) ou } \\
\text { particípio passado. }\end{array}$} & $\begin{array}{l}\text { Sager, Dungworth e } \\
\text { McDonald } \\
\text { (1980) }\end{array}$ & $\begin{array}{l}\text { Amber light (luz QUE É âm- } \\
\text { bar). } \\
\text { Fixed gauge (calibrador QUE } \\
\text { É fixo). }\end{array}$ \\
\hline
\end{tabular}




\begin{tabular}{|c|c|c|c|c|}
\hline & \multicolumn{2}{|c|}{$\begin{array}{l}\text { Tipo de relação } \\
\text { semântica }\end{array}$} & Autores & Exemplo $^{6}$ \\
\hline \multirow[t]{2}{*}{13} & $\begin{array}{l}\text { NÚCLEO = } \\
\text { Instrumento } \\
\text { que opera no } \\
\text { determinante }\end{array}$ & \multicolumn{3}{|c|}{$\begin{array}{l}\text { Que opera no__ (núcleo)? } \\
\text { Onde opera o___ }\end{array}$} \\
\hline & \multicolumn{2}{|c|}{$\begin{array}{l}\text { O núcleo expressa o } \\
\text { instrumento que opera no } \\
\text { determinante }\end{array}$} & $\begin{array}{l}\text { Sager, Dungworth e } \\
\text { McDonald } \\
\text { (1980) }\end{array}$ & $\begin{array}{l}\text { Heat exchanger (o trocador } \\
\text { QUE OPERA NO calor). } \\
\text { Skin exchange (a troca QUE } \\
\text { OPERA NA fuselagem). }\end{array}$ \\
\hline \multicolumn{5}{|c|}{ Processos e operações } \\
\hline & \multicolumn{2}{|c|}{$\begin{array}{l}\text { O determinante } \\
\text { geralmente especifica } \\
\text { o sujeito ou objeto do } \\
\text { núcleo que geralmente } \\
\text { corresponde a uma ação } \\
\text { verbal. }\end{array}$} & $\begin{array}{l}\text { Sager, Dungworth e } \\
\text { McDonald } \\
(1980)\end{array}$ & $\begin{array}{l}\text { Temperature change (a change } \\
\text { of temperature) } \\
\text { Emergency landing }\end{array}$ \\
\hline
\end{tabular}

Fonte: Elaboração própria a partir de Downing (1977), Levi (1978), Sager, Dungworth e McDonald

(1980), Shawcross (1992a) e Adams (2001).

Ainda que não estivessem repetidas, as relações de número doze (o determinante expressa uma propriedade) e de número treze (o núcleo expressa o instrumento que opera no determinante), sugeridas por Sager, Dungworth e McDonald (1980), foram mantidas, pois verificamos que estavam presentes em nosso corpus de estudo. Pela mesma razão, mantivemos a relação sugerida por Sager, Dungworth e McDonald (1980) para as bases da categoria processos e operações.

Sugerimos, portanto, essa matriz de relações semânticas (Quadro 13) como base para a análise das UEPNs do âmbito da aviação por acreditarmos que ela é variada o suficiente sem ser muito específica, podendo ser entendida por não especialistas, por exemplo, por alunos de ESP para aviação.

\section{Considerações finais}

Este trabalho teve por objetivo apresentar e caracterizar as UEPNs, ressaltando a sua aplicabilidade nos textos especializados dos manuais de aviação. Observamos e descrevemos as UEPNs a partir da identificação de suas características e regularidades enquanto inseridas no conjunto de textos especializados, buscando conhecer seus padrões formais e de seu conteúdo semântico, verificando regularidades e também estabelecendo generalizações. 
Levando em conta as perspectivas apresentadas neste trabalho, acreditamos que cada âmbito especializado apresenta um número de relações semânticas típicas e outras equivalentes às da língua geral. Assim, propusemos uma matriz de relações semânticas para servir de base para a análise das UEPNs em textos de aviação (Quadro 13) que parte da sobreposição das três listas propostas para a língua geral por Downing (1977), Levi (1978) e Adams (2001) e das duas listas para linguagens de especialidade propostas por Sager, Dungworth e McDonald (1980) e Shawcross (1992a).

Esperamos que nossas reflexões sobre como se processa a interpretação das UEPNs, apoiada em uma matriz de relações semânticas para a análise dessas unidades, possam contribuir para o ensino/aprendizagem de ESP para aviação, assim como ser aplicadas a outros âmbitos e outras linguagens de especialidade.

BOCORNY, A. E. P. Long Specialized Noun Phrases (LSNP) in Aviation Manuals. Alfa, São Paulo, v.58, n. 3, p. $645-676,2014$.

- ABSTRACT: The aim of this paper is to present and characterize the long specialized noun phrases (LSNPS) as part of a larger work involving the development of a glossary for students of English for aviation. Initially, we address the issue of conceptual and denominational diversity associated with the LSNPS. Given the lack of consensus in the literature on the subject, we seek to clarify where the denominational difference actually corresponds to a conceptual difference. Subsequently, we formally characterize the units, list the elements that can compose them and describe their relationships. Finally, we review the literature regarding the problems and solutions relating to the interpretation of the LSNPS, usually resulting from the large compression of information in a limited number of words, which makes the understanding of these units particularly difficult by non-specialists. For this purpose, we review the works of authors such as Downing, Sager, Lehrberger, Trimble, and Shawcross. We then resume some issues that should be taken into account when interpreting the LSNPS, supported by a matrix of semantic relations for the analysis of these units within the context of aviation.

- KEYWORDS: Linguistics. Terminology. LSNP. Translation. ESP. Language of aviation.

\section{REFERÊNCIAS}

ADAMS, V. Complex words in English. London: Pearson, 2001.

BARKER, K. A trainable bracketer for noun modifiers: advances in artificial intelligence. Lecture Notes in Computer Science, New York, v.1418, p.196-210, 1998.

Noun modifier relationship analysis in the TANKA system. Ottawa: University of Ottawa, 1997.

BIBER, D. et al. The Longman grammar of spoken and written English. London: Longman, 1999. 
CABRÉ, M. T.; ESTOPÀ, R. Unidades de conocimiento especializado, caracterización y tipología. In: CABRÉ, M. T.; BACH, C. (Org.). Conexixement, llenguatge i discurs especialitzat. Barcelona: Institut Universitari de Lingüística Aplicada: Universitat Pompeu Fabra: Documenta Universitaria, 2005. p.11-93.

CAFÉ, L. La description et l'analyse des unités terminologiques complexes en langue portugaise (variété brésilienne): une contribution à l'automatisation de la Banque de Données Terminologiques du Brésil (Brasilterm). 1999. 250 f. Tese (Doutorado em Linguística) - Université Laval, Québec, 1999. Tomos I e II.

CELCE-MURCIA, M.; LARSEN-FREEMAN, D. The grammar book: an ESL/EFL Teacher's Course. 2. ed. Boston: Heinle \& Heinle, 1999.

DIK, S. C. The theory of functional grammar: complex and derived constructions. Berlin:W. de Gruyter, 1997. v.2.

The theory of functional grammar. the structure of the clause. Dordrecht: Foris Publications, 1989. v.1.

DOWNING, P. On the creation and use of English compound nouns. Language, London, v.53, n.4, p.810-842, 1977.

ESTOPÀ, R. Lês unités de signification spécialisées: élargissant l'objet du travail en terminologie. Terminology, New York, v.7, n.2, p.217-237, 2001.

Extracción de terminología: elementos para la construcción de un SEACUSE (Sistema se Extracción Automática de Candidatos a Unidades de Significación Especializada). 1999. 150 f. Tese (Doutorado em Linguística Aplicada) - Universitat Pompeu Fabra, Barcelona, 1999.

FABRE, C. Interpretation of nominal compounds: combining domain-independent and domain-specific information. In: INTERNATIONAL CONFERENCE ON COMPUTATIONAL LINGUISTICS (COLING), 16., 1996, Stroudsburg. Proceedings... Stroudsburg: Association of Computational Linguistics, 1996. v.1, p.364-369.

FAULSTICH, E. Formação de termos: do construto e das regras às evidências empíricas. In: FAULSTICH, E.; ABREU, S. P. (Org.). Linguística aplicada à terminologia e à lexicologia: cooperação Brasil e Canadá. Porto Alegre: Ed. da UFRGS, 2003. p.11-31.

FININ, T. W. The semantic interpretation of compound nominals. Champaign: University of Illinois at Urbana-Champaign, 1980.

GIRJU, R. et al. On the semantics of noun compounds. Computer Speech and Language, London, v.19, n.14, p.479-496, 2005.

KAGEURA, K. The dynamics of terminology: a descriptive theory of term formation and terminological growth. Amsterdam: John Benjamins Publishing, 2002. 
LEHRBERGER, J. Automatic translation and the concept of sublanguage. In: KITTREDGE, R.; LEHRBERGER, J. (Org.). Sublanguage: studies of language in restricted semantic domain. Foundations of Communication. Berlin:W. de Gruyter, 1982. p.81-106.

LEVI, J. N. The syntax and semantics of complex nominals. New York: Academic Press, 1978.

OSTER, U. Los términos de la cerámica en alemán y en español: análisis semántico orientado a la traducción de los compuestos nominales alemanes. 2003. 542 f. Tese (Doutorado em Tradução) - Departament de Traducció i Comunicació, Universitat Jaume I, Castellón, 2003. Disponível em: <http://www.tdx.cat/ bitstream/handle/10803/10565/oster.pdf? sequence=1 >. Acesso em: 25 jun. 2013.

QUIRK, R. et al. A comprehensive grammar of the English language. London: Longman, 1985.

QUIROZ, G. Los sintagmas nominales extensos especializados en inglés y en español: Descripción y clasificación en un corpus de genoma. 2005. 238 f. Tese (Doutorado em Linguística Aplicada) - Institut Universitari de Lingüística Aplicada, Universitat Pompeu Fabra, Barcelona, 2005.

RIJKHOFF, J. The noun phrase. Oxford: Oxford University Press, 2002.

ROSARIO, B.; HEARST, M. Classifying the semantic relations in noun compounds via a domain-specific lexical hierarchy. In: CONFERENCE ON EMPIRICAL METHODS IN NATURAL LANGUAGE PROCESSING (EMNLP), 1., 2001, Berkeley. Proceedings... Berkeley: University of California, 2001. p.82-90. Disponível em: $<$ http://biotext.berkeley.edu/papers/emnlp01.pdf>. Acesso em: 24 jun. 2013.

SAGER, J. C. Curso práctico sobre el procesamiento de la terminología. Madrid: Fundación Germán Sánchez Ruipérez, 1993. (Biblioteca del libro, 57).

SAGER, J. C.; DUNGWORTH, D.; McDONALD, P. F. English special languages: principles and practice in science and technology. Wiesbaden: Brandstetter, 1980.

SHAWCROSS, P. English for Aircraft.1: documentation handbook. Paris: Belin Editions, 1992a.

English for Aircraft.2: system maintenance. Paris: Belin Editions, 1992b.

TRIMBLE, L. English for science and technology: a discourse approach. Cambridge: Cambridge University Press, 1985.

Recebido em julho de 2013.

Aprovado em setembro de 2013. 